\title{
HOW GREEN THE SUPPLY CHAIN OF APPAREL MANUFACTURING COMPANIES IN SRI LANKA
}

\author{
Dilini S. Manage \\ Faculty of Management and Finance \\ University of Colombo, Sri Lanka \\ dilini.manage12@gmail.com \\ Kumudinei Dissanayake \\ Department of Management and Organization \\ Faculty of Management Studies and Finance \\ University of Colombo, Sri Lanka \\ kumudisa@mos.cmb.ac.lk
}

\begin{abstract}
This research aims to study the Green Supply Chain Management Practices (GSCMPs) adopted and the challenges encountered in achieving a closed-loop supply chain in apparel manufacturing companies in Sri Lanka. By adopting a deductive approach and quantitative survey method and using a self-administered questionnaire, the study collects data from 102 Strategic Business Units of apparel companies located in the Western and North Western provinces of Sri Lanka. Descriptive statistics are used for analysing data. Results indicate that only a few companies have adopted all the considered GSCMPs making the supply chain a closed-loop while the majority of companies are focused on few practices. The most adopted GSCMP among the considered companies is green production, and the least adopted practice is green delivery. High transport cost is identified as the most common challenge that restricted companies from achieving closed-loop supply chain, followed by high inventory cost and lack of staff. These findings imply the lacking areas which need to be addressed in achieving a closed-loop supply chain in the Sri Lankan apparel companies.
\end{abstract}

Keywords: Apparel manufacturers; Closed-loop supply chain; Green supply chain management; Challenges; Sri Lanka. 


\section{Introduction}

Sustainable business operations in manufacturing entities encompass a series of green practices that functioned at different stages in the supply chain process. According to Srivastava (2007), Green Supply Chain Management (GSCM) is "integrating environmental thinking into supply-chain management, including product design, material sourcing, and selection, manufacturing processes, delivery of the final product to the consumers as well as end-of-life management of the product after its useful life" (p.54). Since many of the logistics decisions throughout the supply chain, i.e., facility location, modal selection, sourcing of raw materials, have a direct impact on the environment, in order to minimize the probable impact, those decisions should be taken at the designing stage of the systems (Murphy \& Poist, 2003). Besides, even nearly two decades ago, those two researchers have identified that salvage, scrap disposal, and return goods handling as the most environmentally impacted functions in a supply chain. Despite the above all mentioned facts from previous research findings, it should be noted that neither greening the supply chain nor adopting green practices is the business priority of most apparel companies. Hence, there should be well-developed greening process with unified efforts by all members of the supply chain (Green Jr. et al.,2012) in order to avoid the sub-optimization at upstream and downstream partner level in the supply chain.

With the perceived benefits of environmental-friendly practices, greening initiatives were taken by many firms. They were used as strategies to cost reductions, improve market share, and to develop strong brand image (Min \& Kim, 2012), to generate business value and higher profit (Oliveira et al., 2018), to eliminate waste, improve productivity (Malviya \& Kant, 2016), and to reduce pollution (Murphy, Poist \& Braunschweig, 1995). Further, there are two directions for any given supply chain, i.e., forward and reverse. By adopting latter with forward logistics practices, the supply chain becomes a closed loop. The operations in the supply chain phase from supplier to customer is known as forward logistics and the operations take place backward is known as reverse logistics. 
Specifically highlighting the benefits of reverse logistics, Srivastava and Srivastava (2005) claimed that reverse logistics activities are profitable. More elaborately, Srivastava (2007) has stated that reverse logistics result in "reduced use of virgin materials and other resources" (p.56), which confirms with the argument of $\mathrm{Wu}$ and Dunn (1994) in which they emphasise reverse logistics as a strategy to source reduction. Moreover, only if the forward flow of materials or finished goods movement are considered at each stage of the supply chain, the waste will be piled up. Again, if environmentally-friendly disposal methods are not followed, the adverse effects on the environment, which is against adopting GSCMPs at large, will be increased.

Even though GSCM has been defined as incorporating environmentally-benign practices into every aspect of supply chain management from product design to product's end of life management (Srivastava, 2007), most of the recent researches have focused on greening at only one phase of the supply chain, which is either from supplier to customer (forward flow) or from customer to supplier (reverse flow) and not the closed-loop supply chain as a whole (Holt \& Ghobadian, 2009). Further, implying the importance of considering reverse logistics activities in future research, it has been identified that future corporate trends would be towards closed-loop supply chains (Zhu et al., 2008a). Nevertheless, there is a theoretical gap visible still in the practice.

As afore mentioned, past research studies on GSCMPs are not scant. However, they have been conducted in different contexts and as per Soda et al., (2015) the findings are subject to the context and causes for variation may be the "heterogeneity of environmental management practices adopted by the firm and industry" (Zhu \& Sarkis, 2007, p.4335). Besides, Srivastava and Srivastava (2005) stated that the previous studies that focused on reverse logistics have mainly chosen the contexts such as electronics, pharmaceuticals, tyres, photocopiers, automobiles, computers, mail orders, cosmetics, breweries and still there is a need for more research on reverse logistics of other fields which have a connection with the product life cycle.

Manufacturing sector in general, and textile industry in particular are proven to consume a substantially higher amount of toxics, and in turn bear the corporate 
social responsibility to protect the environment (Wu, Ding \& Chen, 2012). Textile industry is known for their extensive use of water and chemical substances in the manufacturing processes (Lai, Hsu \& Chen,2012). In the case of Sri Lanka, in 2018, apparel sector has contributed 5.99 percent to GDP and has generated approximately 30.8 percent of employment opportunities (Annual Report of CBSL, 2018). And also, manufacturers of textiles and manufacturers of wearing apparels altogether account for 2773 establishments, 762,283 persons engaged in and LKR 1.2 trillion worth output (Labor Demand Survey, 2017). At the same time, the apparel industry in Sri Lanka has consumed 14 percent of energy of all industrial sectors, which accounts to 29 percent from the country's energy demand. (Sri Lanka Sustainable Energy Authority, 2017).

When considering the current situation in the apparel industry in Sri Lanka, it is evident that the scrap rate at apparel manufacturing plants is at a high level and it is mainly due to lack of material recycling. As a result, they are spending huge cost on dumping textile waste which ultimately affects the internal performance of the organization. Further, it has been estimated that the apparel industry in Sri Lanka is generating textile waste between 19,000 to 38,000 tons annually since the cutting waste is approximately ranging between 10 to 20 percent of fabric consumption (Jayasinghe et al., 2010). Not only that currently apparel companies are paying a higher cost for third party companies for dumping the waste which affects the total cost of the operation and ultimately the economic performance of the company. Despite the situation is as such, in Sri Lankan apparel companies adoption of GSCM practices have limited to green operations such as energy conservation, waste reduction (De Silva \& Rupasinghe, 2016) and as it seems reverse logistics practices such as recycling, reusing are not practised to a satisfactory level. Thus, considering its economic contribution, high resource and energy consumption, huge output, textile waste, waste dumping cost and larger number of establishments, it is evident that necessity for apparel companies in Sri Lanka to adopt GSCMPs in their operations.

Despite Sri Lankan apparel companies have been adopting GSCMPs for some time, there is dearth of knowledge of the nature of GSCMPs adopted, the status of the adoption of closed-loop supply chain, and any challenges they encounter in 
adopting a closed-loop supply chain. Filling this vacuum would help understand the extent of greening efforts made in and around the supply chain of apparel manufacturers in Sri Lanka. This knowledge would help provide implications for apparel manufacturers and other stakeholders for eliminating barriers in greening the supply chain. Accordingly, the aims of the present study are (a) to identify the GSCMPs that have been adopted by the apparel companies in Sri Lanka, and (b) to examine the challenges that restricted achieving a closed-loop supply chain in the apparel companies.

\section{Literature Review}

\subsection{Green supply chain management}

GSCM has its roots in both environmental management and supply chain management disciplines. Incorporating the Green component in supply chain management exhibits the influence of it on supply chain management and the relationship between the supply chain management and the natural environment (Srivastava, 2007). Since the supply chain is composed of a network of suppliers, distributors and consumers where the activities such as manufacturing, transportation between suppliers and customers, storing, consuming and disposing are taken place (Zhu \& Sarkis, 2004), supply chain management has been defined as the process of managing relationships, information and material flows across the organizations that are involved in, with the intention of providing enhanced customer service, economic value to the customers and all supply chain partners (La Londe \& Bernard, 1997). Proper integration of supply chain processes, coordination and strategic alignment is required throughout the supply chain for satisfying the end-user (Green jr. et al., 2008).

As far as researcher's knowledge, the most widely used and more comprehensive definition for GSCM has been explained Srivastava (2007), "integrating environmental thinking into supply-chain management, including product design, material sourcing and selection, manufacturing processes, delivery of the final product to the consumers as well as end-of-life management of the product after its useful life" (p.54). Furthermore, Min and Kim (2012) also contributed to making 
the definition of Srivastava (2007) more comprehensive by adding "incorporation of environmentally friendly initiatives into every aspect of supply chain activities" (p.40). And also, maybe to emphasize the broader scope, Min and Kim highlighted the activities which have not been specifically mentioned in Srivastava's definition; i.e., product development, packaging, storing, retrieving and disposal. Confirming the findings of requirements to make broader the traditional scope of supply chain management in GSCM, Beamon (1999) also has noted that GSCM should consist of mechanisms for product and package recycling, reusing, remanufacturing and performance measurements in addition to its traditional functions.

The above definitions imply the importance of integrating environmental concerns into supply chain management operations. Accordingly, the working definition of GSCM in the present study is noted to be "incorporating environmental benign practices and environmental thinking into every aspect of the supply chain from inbound operations to production, outbound operations and reverse logistics".

\subsection{GSCM practices}

Based on the understanding of the scope and the purpose of the GSCM, authors have identified different GSCMPs in their studies. GSCMPs comprises a series of inter- organizational activities which have been aroused to mutual problem solving (environmental collaboration) and inspection and risk minimization (environmental monitoring), further, it includes both internal and external activities through technological and logistics integration with primary suppliers and major customers (Vachon \& Klassen, 2006). With a similar view but in a broader level of integration, Agi and Nishant (2017) also identified GSCMPs as internal level activities and external level activities that needs to be conducted with "upstream and downstream supply chain partners through the implementation of a number of environment-friendly practices such as practices oriented towards reducing wastes and energy consumption, reusing, remanufacturing, or recycling the products, the eco-design and the reverse logistics"(p.351). Although the concept of integrating the supply chain partners is the same, Vachon and Klassen (2006) have identified a different set of practices pertaining to GSCM. i.e. environmental collaboration with primary suppliers and major customers, environmental monitoring with 
primary suppliers and major customers, technological integration with primary suppliers and major customers and logistical integration with primary suppliers and major customers. However, it should be noted that practices identified by Agi and Nishant (2017) are making a closed-loop supply chain which is absence in the practices of Vachon and Klassen (2006). Accordingly, inbound practices, operation practices, outbound practices (Rao \& Holt, 2005), reverse logistics, management support, and customer support (Lakshmimeera \& Palanisamy,2013) have been identified as the GSCMPs that make the supply chain a closed loop.

It should be noted that uniformity of GSCMPs is lacking in the literature (Murphy $\&$ Poist, 2003). Nevertheless, there are GSCMPs which could be found commonly in past studies, i.e. internal environmental management (Zhu \& Sarkis,2004; Zhu \& Sarkis,2006; Zhu \& Sarkis,2007; Zhu et al,2013; Vanalle et al., 2017), eco design (Zhu \& Sarkis,2004; Zhu \& Sarkis,2006; Zhu \& Sarkis,2007, Green jr et al., 2012; Zhu et al, 2013), green purchasing (Zhu \& Sarkis,2006; Zhu \& Sarkis,2007; Green jr et al., 2012; Zhu et al,2013; Vanalle et al, 2017), customer cooperation (Zhu \& Sarkis,2006; Zhu \& Sarkis, 2007; Zhu et al,2013; Vanalle et al., 2017) and investment recovery (Zhu \& Sarkis,2004; Zhu \& Sarkis,2006; Zhu \& Sarkis,2007; Green jr et al., 2012; Zhu et al,2013; Vanalle et al., 2017), External GSCM (Cooperation with customers and suppliers) (Zhu \& Sarkis, 2004; Green jr et al., 2012). Furthermore, from the above practices, it can be realized that GSCMPs that makes the linear supply chain into a closed-loop has not been taken into the account by many recent researchers.

Similarly, there are studies in which those GSCMPs has been categorized based on different criterion. For example, Laosirihongthong et al., (2013) have presented two types of practices namely proactive and reactive practices which include the practices of green purchasing, eco-design, reverse logistics and legislation, regulation respectively. Moreover, it has been argued that while proactive strategies lead organizations for voluntary adoption of GSCMPs, reactive strategies influence the adoption under regulatory, customer and competitive pressures (Mitra \& Datta, 2014). In addition, another categorization of GSCMPs can be found as internal and external GSCMPs (Zhu et al., 2013) in which, eco-design and internal environment management have been identified as internal practices while green purchasing, 
customer corporation and investment recovery have been listed under the external practices. Further, even though Vanalle et al., (2017) also have considered all the above mentioned most cited GSCMPs, in their findings they have identified that the most effective practices implemented are Internal environmental management, green purchasing and customer cooperation.

As per Green jr et al., (2012), if an organization seeks positive performance improvement through the GSCMPs adoption, it is required that the strategic level and the information systems of the organization should be capable of integrating the partners in the supply chain. Moreover, they claim that the successful implementation of GSCMPs such as green purchasing, cooperation with customers, eco-design and investment recovery are leading to an improved environmental and economic performance which support improved operational and organizational performance. Considering all definitions and practices stated above, it is noted that GSCMPs should be encompassed all the activities from supplier to customer and reverse logistics. Since there is no uniformed framework to identify the GSCMPs which are to be adopted and aligning with the GSCM definition of Srivastava (2007), GSCMPs on inbound, production, outbound and reverse logistics will be selected by the researcher as the GSCMPs to be studied in the research.

\subsection{Reverse logistics}

Previous studies and reviews related to GSCM had a limited focus and narrowed perspective where a comprehensive, integrated view of the research area is lacking. However, due to the growing concern on the environment, reverse logistics had created substantial interest (Srivastava \& Srivastava, 2005). Hence, to make the work comprehensive and integrated, all the aspects of GSCM, particularly including reverse logistics, are to be taken into consideration (Srivastava, 2007). Accordingly, the concept of GSCM has become comprehensive by incorporating both forward and reverse flows in the supply chain which further get confirmed with the GSCM definition of Srivastava (2007). If the supply chain considers only the forward flow of materials or finished goods movement, at each stage of the supply chain, the waste will be piled up. Again, if the environmental-friendly 
disposing methods are not followed, adverse effects on the environment will be increased. Both these situations are against the objectives of GSCMPs at large and reverse logistics. Moreover, repair, recondition, remanufacturing, recycle, disposal (Khor \& Udin, 2013), repacking, returns processing and salvage (Rogers $\&$ Tibben-Lembke, 2001) have been identified as the reverse logistics activities.

The phase of the supply chain from customer to the supplier is known as reverse logistics and it has been defined as "the process of planning, implementing, and controlling the efficient, cost-effective flow of raw materials, in-process inventory, finished goods, and related information from the point of consumption to the point of origin for the purpose of recapturing or creating value or proper disposal" (Rogers \& Tibben-Lembke, 1999, p.2). Further, recapturing or creating value through reverse logistics can be elaborated with the explanation of Srivastava (2007), in which he stated that "reduced use of virgin materials and other resources" (p.56) as one of the objectives of reverse logistics. Not as broad as the previous definition but in somewhat a similar view, reverse logistics is defined as an operating practice that recovers materials in order to enable re-entry at forward supply chain to make new or used products by means of material reusing, remanufacturing or recycling (Hervani et al., 2005). On the other hand, Wu and Dunn (1994) argued the emphasis of reverse logistics is to source reduction and substitution over reuse and recycling since source reduction is the best way to address environmental issues.

When it comes to the drivers which have been driven the reverse logistics function, it has been identified that exponential growth of electronic waste, higher rate of equipment obsolescence, the residual value of the product, ability to deploy reusable content in forward supply chain and local government regulations to extending producer responsibility have influenced to adopt reverse logistics practices (Khor \& Udin, 2013). It has been identified the importance of incorporating less traditional functions such as return goods handling, salvage and scrap disposal in logistics (Murphy \& Poist, 1995). And also, Wu and Dunn (1994) stated that consumers have the right to leave packaging materials at retail stores and it is their responsibility to dispose properly. However, previous research studies have been focused either forward logistics or the reverse logistics separately and not the closed-loop supply chain as a whole (Holt \& Ghobadian, 
2009), which supports the claim that has been made by Srivastava (2007) that lack of a comprehensive, integrated view of supply chain researches. Also, he stated that the studies that focused on reverse logistics have mainly chosen the contexts such as electronics, pharmaceuticals, tyres, photocopiers, automobiles, computers, mail orders, cosmetics, breweries and still there is a need for more research on reverse logistics in particular its connection to the product life cycle. Nevertheless, when considering the scope of this research which is on GSCMPs adoption in the Sri Lankan Apparel industry, the researcher is focusing on the life cycle of the product from the raw material stage until it is safe disposal. Thereby, to some extent, this research could contribute to the gap identified by Srivastava (2007) in his review article.

As per the literature, the reverse logistics process consists of four stages, namely collection, inspection, pre-processing and distribution (Srivastava \& Srivastava, 2005). Furthermore, in the collection stage, products to which reverse logistics apply is determined. Then products are collected and if required transport the collected products for rework and refurbish. Inspection may be performed either at the time of collecting or afterwards. In the next stage, products are sorted, segregated and then depending on the requirement partial or complete disassembles, minor repairs or refurbishments are carried out. Finally, with the product's location and distribution, process becomes complete.

The study of Laosirihongthong et al., (2013) on Thailand manufacturing companies, has shown that reverse logistics practices had no significant impact on the GSCM performance, However, in contrast, Srivastava and Srivastava (2005) claimed that reverse logistics activities are profitable for the product categories they have considered beyond a certain minimum quantity of returns. At the same time, some researchers argue that the effectiveness of product dispositions (repair, recondition, remanufacturing, recycle and disposal) is dependent on the product green design (Khor \& Udin, 2013). Thereby it is evident that if an organization intends to execute a closed-loop supply chain, it has to be initiated at the product designing stage and in order to be received the benefits of reverse logistics, the entire supply chain should be well planned from the very first designing stage. 


\subsection{Challenges in adopting closed loop supply chain}

Despite above-mentioned concerns, regulatory requirements and perceived benefits of a closed-loop supply chain still the companies in developing countries pay a less attention on reverse logistics practices. For instance, due to more pricesensitivity and less environmentally sensitivity, consumer and legislation pressure on reverse logistics in India is virtually non-existent (Srivastava \& Srivastava, 2005). Further, lack of awareness on the perceived benefits of reverse logistics practices is one of the major reasons that Indian automobile companies have not adopted reverse logistics in their supply chains (Mudgal, Shankar, Talib, \& Raj, 2010). Thus, it is evident that even though it has been proved the benefits of GSCMPs, in particular, reverse logistics, the adoption of practices is subject to many reasons and barriers. Thereby it is necessary to identify the reasons not adopting reverse logistics practices which make the supply chain a closed-loop.

As per Rogers and Tibben-Lembke (2001), the greatest barrier for implementing reverse logistics is the importance of reverse logistics relative to other issues, followed by company policies, lack of systems, competitive issues, management inattention, personal resources, financial resources and legal issues. In the study of Srivastava (2011) he has identified the barriers as internal and external. Accordingly, it has been identified that lack of awareness, lack of top management commitment, lack of strategic planning and lack of well-trained employees as the internal barriers while lack of laws and regulations to enforce stakeholders as the external barrier, in the electronic industry of China. Further, Hall, Huscroft, Hazen and Hanna, (2013) stated that disposition of returned goods, communication, logistics management, transportation, cost management and training, customer errors, establishing reverse logistics standards/processes, information technology to support reverse logistics, product identification and visibility as the inbound reverse logistics challenges. Also, as the outbound logistics challenges, communication, receipt of credit/ replacement product, establishing transport and logistics standards/processes, process visibility and training have been identified. 


\subsection{Theories related to GSCMPs adoption}

Literature on GSCMPs imply that how researchers have attempted to make connection between the Management theories and environmental-friendly operations of businesses.

\subsubsection{Stakeholder Theory}

Freeman (1999) states that organizations would pay attention to stakeholders; any individual or group who can affect the firm's performance or who is affected by the achievement of the organization's objectives, if they need to be effective and strive the relationship with the stakeholders.

Being part of the interconnected system, supply chain operations as well as decisions could be affected on numerous parties i.e., suppliers, customers, internal employees, community etc. Thus, before making supply chain related decisions, organization should be focused on the effect of those decisions on its stakeholders at large.

As afore mentioned, implementation of green practices in a supply chain cannot be achieved by an effort of a single entity, it should be extended from the organizational boundary to supply chain level (Preuss,2002). Further, Vachon and Klassen (2006) have stated that supply chain managers are forced to address social and environmental issues in their firms as well as their supply chain partners, which also emphasize the relevance of stakeholder theory in adoption of GSCMPs.

\subsubsection{Institutional Theory Perspective}

Institutional theory implies that strong motivation behind a firm's socially responsible behavior comes with the influence of institutions and interconnected organizational networks within which the firm operates (Zhu et al., 2013).

Being a part of the society, every organization is bound with different legal and social requirements in order to sustain their operations. Since the ultimate objective of any supply chain is to satisfy the customers and other stakeholders, supply chains are operated in a manner that fulfills both customer and legal requirements (Laosirihongthong et al., 2013). Hence, if consider as to why 
companies are adopting GSCM practices, the pressure from government agencies, national and international regulations have been mainly influenced the adoption of environmentally responsible behavior (Zailani, Eltayeb, Hsu \&Tan, 2012) in addition to the pressures from social norms and competitors on the same industry.

\section{Research Methodology}

This is an explanatory research (Saunders et al., 2009) which intends to identify the adoption of GSCMPs and the challenges encountered in adopting a closedloop supply chain in the apparel companies. This study adopts a deductive approach, survey strategy and a quantitative method by using a self-administered questionnaire survey for data collection which is suited to the nature of the enquiry (Forza, 2002). Large scale export-oriented apparel manufacturing companies with 200 or more employees engaged-(DCSSL, 2015) in the Western and NorthWestern provinces of Sri Lanka where the majority of large apparel manufacturers are located (Export Development Board, 2020), represented the population of the study. Larger firms are more likely to adopt GSCMPs (Min \& Galle, 2001; Zhu \& Sarkis, 2004) and firms which are involved in exporting seem to be more pressurized for adopting GSCMPs by their international customers (Mitra \& Datta, 2014). Since the objective of the study is to identify GSCMPs adopted and challenges that restricted achieving a closed-loop supply chain in the Apparel companies in Sri Lanka, the unit of the analysis will be at the plant level.

Having the difficulty of identifying desired respondents for the sample, due to the reason that all apparel manufacturers are not adopting GSCMPs, and further, due to the prevailing COVID-19 pandemic situation, snowball sampling was adopted as the sampling method. After getting confirmed that a company is adopting GSCMPs, the questionnaire was shared with its Strategic Business Units (SBUs) through the Sustainability Manager or Compliance Manager who provided the details of other SBUs. The Google form (questionnaire) was shared with an identified respondent in a particular SBU. This data collection was continued until "either no new cases are given or the sample size is as large as is manageable" (Saunders, et al., 2009). 
Based on existing literature, four categories of GSCMPs in manufacturing companies were identified namely; inbound operations, green operations, outbound operations and reverse logistics. Green purchasing has been clustered under the inbound operations (Min \& Galle, 2001; Rao, 2007) and as the indicators for green operations, eco-design and green production were identified (Lakshmimeera \& Palanisamy, 2013). Besides, green warehousing, green delivery (Kuar et al., 2016; Wu \& Dunn, 1995) and customer cooperation, investment recovery (Zhu et al., 2013) have been clustered under outbound operations and reverse logistics respectively. In preparing the questionnaire, the variables and measures were adapted from Kuar et al., (2016), Zhu et al., (2013), Lakshmimeera and Palanisamy (2013), Hemachandra (2009), Rogers and Tibben-Lembke (2001).

Once the reliability and validity of measures were confirmed through the preliminary analysis of pilot test data, through the Sustainability Managers or Compliance Managers of those GSCMPs adopted companies, the final questionnaire was shared with Operations Managers, Operations Executives, Supply Chain and Operations Managers, Supply Chain Managers, Supply Chain Executives in the selected SBUs who confirmed their comfortability in responding to an online self-administered questionnaire survey. The GSCMPs were identified by asking respondents to mark the current status of GSCMP adoption in five points Likert scale ranging from 1 (not considering), 2 (planning to consider), 3 (considering it currently), 4 (initiated implementation), and 5 (implementing successfully). To examine the challenges that hindered the adoption of GSCMPs we used five points Likert scale ranging from 1 (strongly disagree) to 5 (strongly agree). In order to avoid the common method bias, as a procedural remedy, reverse code items were used. The number of completed responses received were 102 .

\section{Analysis and findings}

\subsection{Demographic details of companies and respondents}

Table 1 presents the descriptive overview of the demographic characteristics of the companies and the respondents. 
Table 1: Company and Respondent Profile

\begin{tabular}{|c|c|c|}
\hline & Total & Percentage \\
\hline \multicolumn{3}{|c|}{ Company Type } \\
\hline Dying and Processing company & 21 & $20.28 \%$ \\
\hline Raw Material Manufacturing & 41 & $40.19 \%$ \\
\hline Embellishment & 27 & $26.47 \%$ \\
\hline Sawing Plant & 55 & $53.92 \%$ \\
\hline \multicolumn{3}{|c|}{ Number of Employees } \\
\hline$>250$ & 13 & $12.75 \%$ \\
\hline $201-250$ & 11 & $10.78 \%$ \\
\hline $151-200$ & 13 & $12.75 \%$ \\
\hline $100-150$ & 65 & $63.73 \%$ \\
\hline Total & 102 & $100 \%$ \\
\hline \multicolumn{3}{|c|}{ Number of years from its Establishment } \\
\hline $35-31$ & 10 & $9.80 \%$ \\
\hline $30-26$ & 13 & $12.75 \%$ \\
\hline $25-21$ & 22 & $21.57 \%$ \\
\hline $20-16$ & 39 & $38.24 \%$ \\
\hline $15-11$ & 12 & $11.76 \%$ \\
\hline $10-06$ & 06 & $5.88 \%$ \\
\hline $05-01$ & 00 & 00 \\
\hline Total & 102 & $100 \%$ \\
\hline \multicolumn{3}{|c|}{ Designation of the respondent } \\
\hline Operations/ Supply Chain Manager & 25 & $24.51 \%$ \\
\hline Assistant Manager (Warehousing/ & 30 & $29.41 \%$ \\
\hline Senior Executive (Supply Chain/ & 16 & $15.68 \%$ \\
\hline Executive (Technical/ Supply Chain/ & 31 & $30.39 \%$ \\
\hline Total & 102 & $100 \%$ \\
\hline
\end{tabular}

The majority of the SBUs that responded in the survey represented more than one type of business which were adapted from the study of Hemachandra (2009). Accordingly, among the 102 respondents, 21 (20.28\%) are from Dyeing and Processing companies while $41(40.19 \%)$ are Raw Material Manufacturing companies. Also, $27(26.47 \%)$ and $55(53.92 \%)$ are respectively from Embellishment and sawing plants. In the present study, as the raw material 
manufacturing companies both fabric and yarn manufacturing companies were considered. Sewing plants are where the clothes are mending. Dyeing and processing companies were the companies where pre-treatments such as washing, bleaching, dyeing were carried out for fibers, yarn and fabrics. In embellishment plants embroidering and printing by which colors were applied on the fabric are performed.

Of hundred and two respondents, $13(12.75 \%)$ are working in companies where there are more than 250 employees and $11(10.78 \%)$ are in companies that have employees in between 201 and 250 . Thirteen (12.75\%) and $65(63.73 \%)$ employees are from companies in which there are 151 to 200 and 100 to 151 employees respectively. It should be noted that respondents were asked to add only the number of office workers (excluding the factory workers) when mentioning the number of employees in the questionnaire. Nevertheless, since the snowball sampling method was used, it can be ensured that all the respondents are from large, exportoriented companies in Sri Lanka. Further, among the companies which have already adopted GSCMPs, 10 (9.8\%) employees are from the companies which have been established 31 to 35 years back and $6(5.88 \%)$ are from companies that have entered operations less than 10 years ago. All other employees are in between 10 and 31 years and the highest number of employees falls into the category of 16 to 20 years $(38.24 \%)$. Moreover, 31 (30.39\%) respondents are executives, followed by $30(29.41 \%)$ assistant managers.

\subsection{Validity and reliability}

In order to keep the measurement errors at a minimum level, validity and reliability tests need to be done (Field, 2017). Since the constructs of the study were adopted from the literature, the construct validity was tested with Confirmatory Factor Analysis (CFA). As Hair Jr et al., (2017) stated all the loading estimates are significant and within the range of 1.0 and -1.0 .

Moreover, having received a greater than 0.7 Cronbach's alpha for all values further confirm that the measures are reliable and have an internal consistency. 
4.3 GSCMPs that have been adopted by the apparel companies in Sri Lanka

The percentage of the GSCMPs adopted in apparel companies in Sri Lanka are reported in table 2 below.

Table 2: Percentage of adopted GSCM practices

\begin{tabular}{|c|c|c|c|c|c|c|c|c|}
\hline \multicolumn{2}{|c|}{ Practice } & $\begin{array}{c}\text { Green } \\
\text { Purchasing }\end{array}$ & $\begin{array}{c}\text { Eco } \\
\text { Design }\end{array}$ & $\begin{array}{c}\text { Green } \\
\text { Production }\end{array}$ & $\begin{array}{c}\text { Green } \\
\text { Warehousing }\end{array}$ & $\begin{array}{c}\text { Green } \\
\text { Delivery }\end{array}$ & $\begin{array}{l}\text { Reuse of } \\
\text { Materials }\end{array}$ & $\begin{array}{l}\text { Material } \\
\text { Recycling }\end{array}$ \\
\hline $\mathrm{N}$ & Valid & 102 & 102 & 102 & 102 & 102 & 102 & 102 \\
\hline \multicolumn{2}{|c|}{ Percentage } & 0.4510 & 0.5294 & 0.7549 & 0.3333 & 0.1078 & 0.5980 & 0.3725 \\
\hline
\end{tabular}

As per the above table, the most adopted GSCMP is green production which accounts for 75.49 percent followed by reuse of materials (59.8\%). Eco-design was noted as 52.9 percent while green purchasing, recycling, green warehousing and green delivery have noted as 45 percent, 37 percent, 33 percent and 10.78 percent respectively. Hence, the green production can be accepted as the highestrated GSCMP as the entire sample consists of apparel manufacturing companies. The descriptive statistics of the GSCMPs in the study are shown in Table 3 below.

\section{Table 3: GSCMPs - Descriptive Statistics}

\begin{tabular}{|l|r|r|r|r|}
\hline \multirow{2}{*}{} & \multicolumn{2}{|c|}{ Mean } & Std. Deviation & Variance \\
\cline { 2 - 5 } & Statistic & Std. Error & Statistic & Statistic \\
\hline GP & 3.2407 & 0.0661 & 0.66741 & 0.445 \\
\hline ED & 4.1397 & 0.0911 & 0.91979 & 0.846 \\
\hline GW & 3.4902 & 0.0868 & 0.87637 & 0.768 \\
\hline GD & 2.9975 & 0.1106 & 1.11720 & 1.248 \\
\hline CCS & 2.6046 & 0.0815 & 0.82285 & 0.677 \\
\hline IR & 2.4456 & 0.0899 & 0.90797 & 0.824 \\
\hline INBOP & 3.1225 & 0.0996 & 1.00601 & 1.012 \\
\hline INOP & 3.2407 & 0.0661 & 0.66741 & 0.445 \\
\hline OUBOP & 3.8150 & 0.0680 & 0.68623 & 0.471 \\
\hline RL & 2.8011 & 0.0753 & 0.76051 & 0.578 \\
\hline GSCMP & 2.9203 & 0.0818 & 0.82628 & 0.683 \\
\hline
\end{tabular}


As depicted in Table 3, the mean value of green purchasing (GP) is 3.24, green production (GPR); 4.12, eco-design (ED); 3.50, green warehousing (GW); 3.00, green delivery (GD); 2.60; cooperation with customers and suppliers (CCS); 2.45, and investment recovery (IR); 3.12. These results further justify the results shown in the above table 02 . For an instance, green production has the highest mean and also it is the most commonly adopted GSCMP according to the received responses. Hence, it is evident that all the seven GSCMPs which were found in the literature are practised in different degrees in Sri Lankan apparel companies. However, the adoption of GSCM (3.14) practices as a whole in Apparel companies in Sri Lanka is in a moderate level. A more elaborated view of GSCMP adoption, i.e., responses for each GSCMP is given in Table 4 below.

Table 4: Percentages of responses for each GSCMP

\begin{tabular}{|c|c|c|}
\hline Practice & $\begin{array}{c}\text { Number } \\
\text { of Responses }\end{array}$ & Percentage \\
\hline \multicolumn{3}{|l|}{ Green Purchasing } \\
\hline $\begin{array}{l}\text { Providing design specifications with environmental } \\
\text { requirements to the Suppliers. }\end{array}$ & 29 & 28.43 \\
\hline Suppliers are selected using environmental criteria. & 21 & 20.59 \\
\hline $\begin{array}{l}\text { Compliance with international environmental } \\
\text { regulations in purchasing. }\end{array}$ & 48 & 47.05 \\
\hline Purchase of environment friendly raw materials & 69 & 67.65 \\
\hline Purchase of recycled raw materials. & 62 & 60.78 \\
\hline $\begin{array}{l}\text { Use of environmental-friendly materials in } \\
\text { packaging. }\end{array}$ & 40 & 39.22 \\
\hline Use of recycled packaging materials. & 39 & 38.24 \\
\hline $\begin{array}{l}\text { Cooperation with suppliers for use of } \\
\text { non-hazardous materials. }\end{array}$ & 65 & 63.73 \\
\hline Conducting periodic Environmental audits for & 43 & 42.17 \\
\hline \multicolumn{3}{|l|}{ Eco design } \\
\hline Design of products with recycled materials. & 51 & 50.00 \\
\hline Design of products for less energy and material & 49 & 48.04 \\
\hline
\end{tabular}




\begin{tabular}{|c|c|c|}
\hline $\begin{array}{l}\text { Design of products for reuse, recycle, recovery of } \\
\text { material, component parts. }\end{array}$ & 55 & 53.92 \\
\hline $\begin{array}{l}\text { Design of products to avoid or reduce use of } \\
\text { hazardous materials. }\end{array}$ & 62 & 60.78 \\
\hline Design of process for minimization of waste. & 67 & 65.68 \\
\hline \multicolumn{3}{|l|}{ Green Production } \\
\hline Use of renewable energy. & 67 & 65.68 \\
\hline Waste reduction. & 92 & 90.19 \\
\hline Reduce emission. & 87 & 85.29 \\
\hline Reduce Carbon foot print. & 70 & 68.62 \\
\hline \multicolumn{3}{|l|}{ Green Warehousing } \\
\hline LEED (Leader in Energy and Environmental & 32 & 31.37 \\
\hline Use of renewable energy (Ex: Solar power). & 41 & 40.19 \\
\hline Use of daylight during daytime. & 34 & 33.33 \\
\hline Space optimization. & 53 & 51.96 \\
\hline \multicolumn{3}{|l|}{ Green Delivery } \\
\hline Environmental-friendly transportation modes. & 18 & 17.65 \\
\hline $\begin{array}{l}\text { Optimization of efficiency through the use of } \\
\text { energy efficient vehicles. }\end{array}$ & 12 & 11.76 \\
\hline Use integrated delivery to reduce transportation. & 46 & 45.09 \\
\hline Optimization of distribution process through better & 48 & 47.05 \\
\hline Use of environmental-friendly technology in & 21 & 20.59 \\
\hline Use of backhauling. & 31 & 30.39 \\
\hline \multicolumn{3}{|c|}{ Cooperation with Customers and Suppliers } \\
\hline Collecting back end of use products from & 16 & 15.68 \\
\hline Collecting back end of use products from & 17 & 16.67 \\
\hline Have recyclable products collection points & 28 & 27.45 \\
\hline Collecting back waste packaging materials from & 19 & 18.63 \\
\hline Cooperation with customers for reusing. & 23 & 22.55 \\
\hline Cooperation with customers for safe disposal. & 30 & 29.41 \\
\hline Cooperation with suppliers to send recyclable & 38 & 37.25 \\
\hline \multicolumn{3}{|l|}{ Investment Recovery } \\
\hline Sales of excess inventories/ materials. & 48 & 47.05 \\
\hline
\end{tabular}




\begin{tabular}{|l|l|l|}
\hline Sales of scrap and used materials & 54 & 52.94 \\
\hline Sales of excess capital equipment & 26 & 25.49 \\
\hline Sales of by product and waste. & 60 & 58.82 \\
\hline
\end{tabular}

Accordingly, the most adopted individual practice is waste reduction (90.19\%) which is followed by emission reduction $(85.29 \%)$ and carbon footprint reduction (68.62\%) respectively. Most importantly, all the above mostly adopted individual practices are under the GSCMP of green production which obtained the highest mean value.

\subsection{Challenges that restricted achieving a closed loop supply chain}

The preliminary survey found that reverse logistics is not practised in some apparel companies owing to certain factors. Thus, eight questions were added to the final questionnaire, in order to identify the challenges that restricted apparel companies in Sri Lanka in achieving closed-loop supply chain. Accordingly, high transportation cost has a mean of 3.84 which is the highest among the challenges, followed by high inventory cost (3.61). Lack of space, lack of staff, lack of customer cooperation and lack of knowledge in handling reverse logistics materials have received the mean values of 3.52, 3.47, 3.22 and 3.07 respectively. Conversely, lack of awareness on benefits of reverse logistics and lack of management support has received the values of 2.47 and 2.55 respectively which denote that Sri Lankan Apparel companies are aware on benefits that can be received through reverse logistics practices and management support also satisfactory to some extent, however the resources that are required to adopt RL at an unsatisfactory level.

Table No 5: Mean values of challenges that restricted adopting reverse logistics practices

\begin{tabular}{|l|c|}
\hline \multicolumn{1}{|c|}{ Challenge } & Mean \\
\hline High Transport Cost & 3.8431 \\
\hline High Inventory Cost & 3.6078 \\
\hline Lack of Space & 3.5196 \\
\hline Lack of Staff & 3.4706 \\
\hline
\end{tabular}




\begin{tabular}{|l|r|}
\hline Lack of Customer Cooperation & 3.2157 \\
\hline $\begin{array}{l}\text { Lack of Knowledge in Handling RL } \\
\text { Materials }\end{array}$ & 3.0686 \\
\hline Lack of Management Support & 2.5490 \\
\hline Lack of Awareness on Benefits of RL & 2.4706 \\
\hline
\end{tabular}

\section{Discussion, Conclusion and Implications}

Despite GSCMPs have been researched for many years in different contexts, still different authors use different GSCMPs for their studies based on their understanding of the scope and the purpose of the GSCM. With related to the first research objective of this study, it was found that the most adopted GSCMP in apparel companies in Sri Lanka is green production (75.49 \%) followed by reuse of materials (59.80\%) and eco-design (52.94\%). Further analysis of individual green production practices revealed that 90.19 percent of respondents have stated that waste reduction is being practiced in their companies while emission reduction and carbon footprint reduction have received 85.29 and 68.62 percent respectively.

Having received the mean values of 4.14 and 3.49 respectively for green production and eco-design indicate that green production is still at the stage of "initiate implementation" while eco-design is at "Considering it Currently" stage. Above finding is aligned with the findings of Ranatunga, Rupasinghe and Liyanarachchi (2017) in which they claim that waste minimization, efficiency resource consumption, energy conservation as the best GSCMPs in Sri Lankan Apparel companies.

In terms of green warehousing and green delivery practices, the findings revealed that the mean score for green warehousing and green delivery are 2.99 and 2.60 respectively. Moreover, optimization of efficiency through the use of energyefficient vehicles $(11.76 \%)$, environmentally friendly transportation modes $(17.65 \%)$ and use of environmentally friendly technology in transportation $(20.59 \%)$ were seemed to be the least adopted individual GSCMPs and the reason could be the high capital cost. Interestingly, as per the study only one third of plants have been adopting green warehousing practice despite many Sri Lankan 
Apparel companies have been awarded with LEED platinum ratings. One of the possible reasons for this mismatch could be those operations such as warehousing and transportation are being carried out by third party logistics service providers and responses for the study were taken only from the internal employees.

Both Cooperation with Customers and Suppliers (2.44) and Investment Recovery (3.12) which are under the practice of Reverse Logistics have received relatively lower mean values. The above values are similar to the findings of Zhu et al., (2013) in their study on Chinese Chemical/ Petrochemical, Electronic, Automobile and Mechanical industries. At the individual practice level of RL, collecting back end of use products from customers for remanufacturing $(15.68 \%)$ is the least adopted practice while sales of by-products and waste $(58.82 \%)$ has obtained the highest percentage. Moreover, as above mentioned, eco-design is still at a primitive stage and this could be due to the fact that Sri Lankan Apparel companies are not collecting back end of use products for remanufacturing whose customers are in abroad. The above confirms the claims of Green Jr et al., (2012) and Zhu et al., (2008a) where they emphasize the importance of moving environmental-friendly practices from organizational level to supply chain level and the effect of cooperation within the company and outside partners for the success of eco-design.

In identifying the challenges that restricted achieving a closed-loop supply chain in the Apparel companies, the findings revealed that high transportation cost (3.84) was the biggest challenge, followed by high inventory cost (3.61) and lack of space (3.52). The above is consistent with the findings of Hall et al., (2013) where they have found that disposition of returned goods, communication, logistics management and transportation as the most rated challenges. In addition, lack of staff (3.47), lack of customer cooperation (3.22), lack of knowledge in handling reverse logistics materials (3.07), lack of management staff (2.55) and lack of awareness on benefits of reverse logistics (2.47) also identified as the challenges in that order. Accordingly, above findings further imply that the lack of resources, knowledge and poor relationship with customers could be the reasons for not adopting reverse logistics practices in a satisfactory level by many Sri Lankan Apparel companies. Conversely, awareness on benefits of reverse logistics and 
management support to adopt reverse logistics practices are at a satisfactory level, which signals positive standpoint of Apparel companies in adopting reverse logistics in future.

The main conclusion drawn from findings is, even though respondents were from GSCM adopted apparel companies in Sri Lanka, only a few companies have adopted all closed-loop GSCMPs and the majority of companies are focused on a few GSCMPs. Further, as per the study, the most adopted GSCMP among the considered companies is green production while the least adopted practice is green delivery. In terms of individual GSCMPs, study reveals that waste reduction, emission reduction and carbon foot print reduction are the most practiced while the optimization of efficiency through the use of energy efficient vehicles, environmental-friendly transportation modes and use of environmental-friendly technology in transportation are the least adopted in Sri Lankan Apparel companies. In addition, it is clear that even though Sri Lankan apparel companies are aware of green purchasing practices, the level of implementation is not satisfactory and this could be due to the poor interrelation among reverse logistics, eco-design and green purchasing practices. Further, we can conclude that Sri Lankan Apparel companies are aware of the perceived benefits of adopting reverse logistics practices and they have the technical knowledge to handle reverse logistics materials and management support, however, high transport cost, high inventory cost, lack of staff and lack of space have restricted them adopting reverse logistics practices which make the supply chain a closed loop.

The main contribution of this study is the revelation of the existing status of the adoption of GSCMPs and the challenges encountered in the apparel companies in Sri Lanka. All stakeholders in the supply chain of apparel companies would be educated with these statuses as well as the unattended green activities some of which are possibilities in the given environments. When considering the theoretical implications of this research, as in this research supply chain was clustered into stages and studied the GSCMPs adoption, it could easily identify the most adopted and the least adopted GSCMP and the cluster in the supply chain. Moreover, in the contemporary business environment, a single company has no control over the entire supply chain as many operations have been outsourced. Thus, if any 
company expects performance improvement by adopting GSCMPs, determining the effect of whole GSCMPs on internal performance based on few practices adopted by the selected company without considering the practices of third-party logistics service providers would lead to incorrect conclusions. Above all, the importance of adopting reverse logistics practices and its interrelation with other GSCMPs i.e., eco-design, green purchasing in closing the loop of supply chain are also highlighted in the present findings. Moreover, the findings of the study indicate that apparel companies in Sri Lanka are not adopting reverse logistics practice mainly due to high costs involved lack of certain resources. They include high transportation cost, high inventory cost, lack of space, lack of staff and lack of customer cooperation, lack of knowledge in handling reverse logistics materials. Hence, the management of apparel companies requires to focus on practical and ground-level issues that have hindered the adoption of GSCMPs rather than merely providing training and awareness programs that are at a satisfactory level.

There are a few limitations to be noted in the present study. As most of the large export-oriented companies are located in the Western and North Western provinces, the study sample was drawn from those two provinces. Difficultly of gaining access to a large sample size made the study less generalizable under some statistical assumptions. However, if all large Apparel companies in Sri Lanka could be accessed for a study, it would strengthen the generalisability of the results. Further, due to the difficulty of accessing the entire apparel supply chain, in this study conclusions on green practices of the supply chain were drawn based on the responses given by a managerial employee of the focal company where the core function is apparel manufacturing. However, if key supply chain partners i.e. suppliers, transport service providers, warehouse service providers could be included in addition to the apparel company, outcome would be more precise. Next, the study was carried out using a single, self-administered online questionnaire, therefore, the findings are fully based on the responses received in that survey. This biasness could be overcome if structured interviews are also conducted with selected respondents. This was impossible for the present study due to the prevailing pandemic situation of the country. 
This study was carried out among large, export-oriented apparel companies, hence, future researches may further examine the GSCMP adoption in other industries as well and bring more insights into this research area. Moreover, apparel manufacturing plants have outsourced some logistics operations such as warehousing, transportation for third party logistics (3PL) service providers. Hence, future research may be able to look into a broader scenario, if they designed to collect responses from 3PL service providers as well. 


\section{References :}

Al-Aomar, R., \& Weriakat, D. (2012, July). A framework for a green and lean supply chain: A construction project application. International Conference on Industrial Engineering and Operations Management Istanbul, 3,289-299.

Barney, J. B. (1991). Firm resources and sustained competitive advantage. Journal of Management, 17, 99-120.

Bartlett, C.A., \& Ghoshal, S. (1993), Beyond the M-form: toward a managerial theory of the firm. Strategic Management Journal, 14(S2), 23-46, doi: 10.1002/ smj.4250141005.

Cohen, S., \& Roussel, J. (2005). Strategic supply chain management: the five disciplines for top performance. McGraw-Hill.

Cosimato, S., \& Troisi,O. (2015). Green supply chain management: Practices and tools for logistics competitiveness and sustainability. The DHL case study. The Total Quality Management Journal, 27 (2),256-276.

Deif, A. M. (2011). A system model for green manufacturing. Journal of Cleaner Production, 19(14), 1553-1559.

Department of Census and Statistics. (2017). Labor demand survey. Retrieved from http:// www.statistics.gov.lk/industry/Labour Demand Survey 2017 Report.pdf.

Fahimnia, B., Sarkis, J., \& Davarzani, H. (2015). Green supply chain management: A review and bibliometric analysis. International Journal of Production Economics, 162, 101-114.

Freeman, R.E. (1999). Divergent Stakeholder Theory. Academy of Management Review, 24 (2), 233-236.

Green, K. W., Zelbst, P. J., Meacham, J., \& Bhadauria, V. S. (2012). Green supply chain management practices: impact on performance. Supply Chain Management: An International Journal, 17(3), 290-305. 
Hair, J. F., Hult, G. T. M., Ringle, C. M., Sarstedt, M., \& Thiele, K. O. (2017). Mirror, Mirror on the Wall: A Comparative Evaluation of Composite-based Structural Equation Modeling Methods. Journal of the Academy of Marketing Science, 45(5), 616-632.

Hall, D. J., Huscroft, J. R., Hazen, B. T., \& Hanna, J. B. (2013). Reverse logistics goals, metrics, and challenges: perspectives from industry. International Journal of Physical Distribution \& Logistics Management, 43 (9), 768 - 785

Hemachandra, D. (2009). A study of voluntary environmental management practices among apparel manufactures in Sri Lanka: Case study approach. International Forestry and Environment Symposium, 18.

Holt, D., \& Ghobadian, A. (2009). An empirical study of green supply chain management practices amongst UK manufacturers. Journal of Manufacturing Technology Management, 20(7), 933-956.

Kaur, G.P., Gupta, P., \& Syal, M. (2016). Adoption of Green Practices in Industrial Buildings: An Action research on Capacity Building of Stakeholders towards Green Factories. International Journal of Sustainable Land use and Urban planning. ISSN 1927-8845, 3 (2), 1-12.

Laari, S., Töyli, J., \& Ojala, L. (2018). The effect of a competitive strategy and green supply chain management on the financial and environmental performance of logistics service providers. Business Strategy and the Environment, 27(7), 872-883.

Lai, K. H., \& Wong, C. W. (2012). Green logistics management and performance: Some empirical evidence from Chinese manufacturing exporters. Omega, 40(3), 267-282.

Lai, R.S.Q., Hsu, L., \& Chen ,J.C.H. (2012). Green Supply Chain Management systems: A case study in the textile industry. Human Systems Management, 31(2), 111-121. 
Lakshmimeera, B., \& Palanisamy, C. (2013). A Conceptual Framework on Green Supply Chain Management. Industrial Engineering Letters, 3(10), 42-51.

Laosirihongthong, T., Adebanjo, D., \& Tan, K. (2013). Green supply chain management practices and performance. Industrial Management \& Data Systems, 113(8), 1088-1109.

Lee, G., Bennett, D., \& Oakes, I. (2000). Technological and organisational change in small- to medium-sized manufacturing companies. International Journal of Operations and Production Management, 20(5),549-72.

Malviya, R., \& Kant, R. (2016). Hybrid decision making approach to predict and measure the success possibility of green supply chain management implementation. Journal of Cleaner Production, 135, 387-409.

Min, H., \& Galle,W.P. (2001). Green purchasing practices of US firms. International Journal of Operations and Production Management, 21(9),1222-38.

Min, H., \& Kim, I. (2012). Green Supply Chain Research: past, present and future. Logistics Research, 4(1-2), 39-47.

Mitra,S., \& Datta, P.P. (2014). Adoption of green supply chain management practices and their impact on performance:an exploratory study of Indian manufacturing firms. International Journal of Production Research, 52(7), 2085-2107.

Murphy, P. R., \& Poist, R. F. (2000). Green logistics strategies: an analysis of usage patterns. Transportation Journal, 40(2), 5-16.

Murphy,P., \& Poist, R. (2003). Green perspectives and practices: a comparative logistics study. Supply Chain Management: An International Journal, 8 (2),122-131.

Oliveira, U.R., Espindola, L.S., Silva, I.R., Silva, I.N., \& Rocha, H.M. (2018). A systematic literature review on green supply chain management: Research implications and future perspectives. Journal of Cleaner Production, 187, 537-561.

Ranatunga, R.S.W.B.S.M ., Rupasinghe, T.D., \& Liyanaarachchi, N. (2017). An Analytical Modelling Approach To Assess The Applicability Of Green Chain Operations: A 
Case Study From The Sri Lankan Apparel Industry. World Conference on Supply Chain Management, 2, 1-16.

Rao, P. (2007). Greening of the supply chain: An empirical study for SMES in the Philippine context. Journal of Asia Business Studies.

Sarkis, J., Zhu, Q., \& Lai, K.H. (2011). An organizational theoretic review of green supply chain management literature. International Journal of Production Economics, 130 (1),1-15.

Soda, S., Sachdeva, A., \& Garg, R.K. (2015). GSCM practices, trends and prospects in Indian context. Journal of Manufacturing Technology and Management. 26, 889-910.

Sri Lanka Sustainable Energy Authority. (2017). Retrieved from http://www. energy.gov.lk/images/energy-balance/energy-balance-2017.pdf

Srivastava, S. K. (2007). Green supply-chain management: a state-of-the-art literature review. International journal of management reviews, $9(1), 53-80$.

Srivastava, S.K., \& Srivastava, R.K. (2005). Profit driven reverse logistics. International Journal of Business Research, 4, 53-61.

The Sustainable Development Goals Report.(2019). United Nations: New York. The World Bank.(2019). Retrievedfromhttps://data.worldbank.org/ indicator/NY.GDP.MKTP.KD.ZG?locations

Vachon,S., \& Klassen,R.D. (2006). Extending green practices across the supply chain The impact of upstream and downstream integration. International Journal of Operations \& Production Management, Vol. 26 No. 7, 2006 pp. 795-821.

Vanalle, R., Ganga, G., Godinho, M., Filho., \&Lucato,W.(2017). Green supply chain management: An investigation of pressures, practices, and performance withintheBrazilianautomotivesupplychain.JournalofCleanerProduction, $151,250-259$. 
Wu, H. H., \& Chang, S. Y. (2015). A case study of using DEMATEL method to identify critical factors in green supply chain management. Applied Mathematics and Computation, 256, 394-403.

Wu, H. J., \& Dunn, S. C. (1995). Environmentally responsible logistics systems. International journal of physical distribution \& logistics management, 25 (2), 20-38.

Zhu, Q., \& Sarkis, J. (2004). Relationships between operational practices and performance among early adopters of green supply chain management practices in Chinese manufacturing enterprises. Journal of Operations Management ,22, 265-289.

Zhu, Q., \& Sarkis, J. (2006). An inter-sectoral comparison of green supply chain management in China: drivers and practices. Journal of cleaner production, 14(5), 472-486.

Zhu, Q., \& Sarkis, J. (2007). The moderating effects of institutional pressures on emergent green supply chain practices and performance. International journal of production research, 45(18-19), 4333-4355.

Zhu, Q., Sarkis, J., \& Lai, K. (2008a). Confirmation of a measurement model for green supply chain management practices implementation. International Journal of Production Economics, 111(2), 261-73.

Zhu, Q., Sarkis, J., \& Lai, K. (2013). Institutional-based antecedents and performance outcomes of internal and external green supply chain management practices. Journal of Purchasing \& Supply Management, 19,106-117.

Zhu, Q., Sarkis, J., Lai, K. H., \& Geng, Y. (2008). The role of organizational size in the adoption of green supply chain management practices in China. Corporate social responsibility and environmental management, 15(6), 322-337. 